\title{
Assessment of the implementation of a nurse-initiated pain management protocol in the emergency department
}

\author{
Avaliação da implementação de um protocolo de manejo da dor iniciado por enfermeiros no departamento de emergências
}

Evaluación de la implementación de un protocolo de manejo del dolor iniciado por enfermeros en el servicio de urgencias

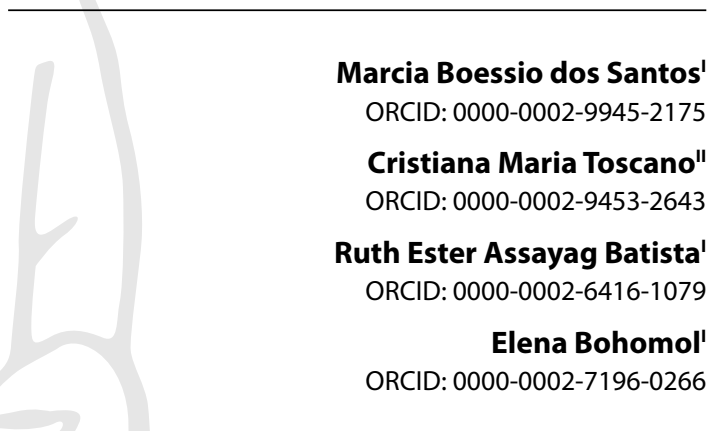

'Universidade Federal de São Paulo. São Paulo, São Paulo, Brazil.

"Universidade Federal de Goiás. Goiânia, Goiás, Brazil.

How to cite this article:

Santos MB, Toscano CM, Batista REA, Bohomol E. Assessment of the implementation of a nurse-initiated pain management protocol in the emergency department.

Rev Bras Enferm. 2021;74(3):e20201303.

https://doi.org/10.1590/0034-7167-2020-1303

Corresponding author:

Elena Bohomol

E-mail: ebohomol@unifesp.br

EDITOR IN CHIEF: Antonio José de Almeida Filho ASSOCIATE EDITOR: Maria Itayra Padilha

Submission: $12-22-2020$

Approval: 02-03-2021

\begin{abstract}
Objectives: to assess the implementation of a nurse-initiated pain management protocol for patients triaged as semi-urgent, and its impact in pain intensity, in the Emergency Department Methods: a prospective cohort study for adult patients with pain who had been triaged as semi-urgent and admitted to the hospital's Emergency Department. Patients who received the intervention (pain-management protocol with analgesic administration) were compared to those who were managed using the conventional approach (physician evaluation prior to analgesic administration). Results: of the 185 patients included, 55 (30\%) received the intervention, and $130(70 \%)$ were managed conventionally. Patients in the intervention group were more likely to have taken pain medication in the 4 hours prior to admission, and reported higher levels of pain at admission and more significant reductions in pain level. Conclusions: despite low protocol adherence, the intervention resulted in higher reported pain relief.

Descriptors: Nurses; Emergencies; Emergency Nursing; Pain Management; Triage.
\end{abstract}

\section{RESUMO}

Objetivos: avaliar a implementação de um protocolo de manejo da dor iniciado por enfermeiros para pacientes triados como semi-urgentes, e seu impacto na intensidade da dor, no Departamento de Emergências. Métodos: um estudo prospectivo de coorte com pacientes adultos com dor triados como semi-urgente e admitidos no Departamento de Emergências do hospital. Os pacientes que receberam a intervenção (protocolo de manejo da dor com administração de analgésico) foram comparados aos que foram manejados com uso da abordagem convencional (avaliação médica antes da administração de analgésico). Resultados: do total de 185 pacientes incluídos, 55 (30\%) receberam a intervenção, e 130 (70\%) foram manejados convencionalmente. Os pacientes do grupo de intervenção apresentaram maior probabilidade de tomar medicação para dor nas 4 horas anteriores à internação, e relataram maiores níveis de dor na internação e reduções mais significativas no nível de dor. Conclusões: apesar da baixa adesão ao protocolo, a intervenção resultou em relatos de maior alívio da dor.

Descritores: Enfermeiras e Enfermeiros; Emergências; Enfermagem em Emergência; Manejo da Dor; Triagem.

\section{RESUMEN}

Objetivos: evaluar la implementación de un protocolo de manejo del dolor iniciado por enfermeros para pacientes clasificados como semi-urgentes, y su impacto en la intensidad del dolor, en el Servicio de Urgencias. Métodos: un estudio prospectivo de cohorte con pacientes adultos con dolor que habían sido clasificados cono semi-urgente y admitidos en el Servicio de Urgencias del hospital. Los pacientes que recibieron la intervención (protocolo de manejo del dolor con administración de analgésico) fueron comparados con aquellos que fueron manejados teniendo en cuenta el enfoque convencional (evaluación médica antes de la administración de analgésico). Resultados: del total de 185 pacientes incluidos, 55 (30\%) recibieron la intervención, y $130(70 \%)$ se gestionaron convencionalmente. Los pacientes del grupo de intervención eran más propensos a haber tomado analgésicos en las 4 horas previas al ingreso, y reportaron mayores niveles de dolor al momento de admisión y una reducción más significativa en el nivel de dolor. Conclusiones: a pesar de la baja adherencia al protocolo, la intervención resultó en un mayor alivio del dolor reportado.

Descriptores: Enfermeras y Enfermeros; Urgencias Médicas; Enfermería de Urgencia; Manejo del Dolor; Triaje. 


\section{INTRODUCTION}

Emergency departments (ED) are key access points to the healthcare system and are primarily aimed at addressing emergencies. However, high demand leads to ED overcrowding, which is associated with longer patient wait times, longer lengths of stay (LOS) in the service, and other adverse patient outcomes, negatively impacting quality of care and costs ${ }^{(1-2)}$.

To best manage ED patient admission processes, several risk classification systems that take into consideration the severity of events have been developed, and triage of patients has been implemented, prioritizing care and allocation of human resources and technologies ${ }^{(3)}$. Nurses are the healthcare professionals who conduct risk classification and triage in $\mathrm{EDs}^{(4)}$.

Pain is the most prevalent and chief complaint for patients visiting EDs. It is characterized as a subjective, individual and complex symptom, described as an unpleasant sensory experience related to multidimensional concepts and past pain experiences, and influenced by social, cultural and emotional aspects ${ }^{(5)}$. When associated with waiting for care, experience in EDs may become unbearable, which may exacerbate patients' clinical status ${ }^{(5-7)}$. As such, pain management is an essential component of quality care delivery in $\mathrm{EDs}^{(8-9)}$.

Pain management is impaired in the context of ED overcrowding $^{(1,6)}$. Timely analgesic administration is required because patients become increasingly sensitive to painful stimuli if pain is uncontrolled for longer periods. Evidence suggests that strategies to enhance pain management in patients admitted to EDs result in more timely administration of analgesics and shorter $\operatorname{LOS}^{(10)}$.

One of these initiatives is the implementation of nurse-initiated pain management protocols based on institutional triage and pain intensity ${ }^{(6-7,10-11)}$.

Traditionally, relief from pain through the administration of analgesics could only be initiated by physicians ${ }^{(12)}$. However, in overcrowded settings, there can be considerable delays between patients' presentation and being seen by ED physicians, and even longer times until analgesic administration ${ }^{(13)}$. With the implementation of nurse-initiated pain protocols, emergency nurses are allowed to administer analgesics, according to pre-defined protocols, without patients first being assessed by ED physicians ${ }^{(11)}$.

Although they were implemented more than a decade ago in developed countries, only more recently have developing countries initiated implementation of nurse-oriented triage programs and pain management protocols for critically ill patients. Few studies assessing the impact of such strategies have been conducted in these settings ${ }^{(11-12,14-17)}$.

In 2009, a nationwide Ministry of Health policy on triage for ED patients using a risk classification system was implemented in $\mathrm{Brazi}^{(18)}$. This triggered hospitals, particularly public hospitals, to initiate ED triaging programs in which patients are assessed by ED nurses, and patient severity ranging from most severe to least severe is defined, taking into consideration patients' reports and vital signs. In 2011, this policy became mandatory for all hospitals in the country, with hospitals being able to adapt the process based on their characteristics and provision of care ${ }^{(19)}$. Brazilian private hospitals use different classification scales, based on some existing triage systems, with the Manchester Triage System being the one most commonly used ${ }^{(20)}$.

\section{OBJECTIVES}

To assess the implementation of a nurse-initiated pain management protocol for patients triaged as semi-urgent, and its impact on pain intensity, in the ED.

\section{METHODS}

\section{Ethical aspect}

The ethical precepts set forth in Resolution 466/2012 of the National Council of Health in Brazil, which is based on the Declaration of Helsinki, were observed. The study was approved by the Research Ethics Committee of the reference institution. All participants signed informed consent forms after being properly informed about the research, respecting their anonymity.

\section{Study design, location and period}

A prospective cohort study was conducted including consecutive adult patients with pain triaged as semi-urgent in the ED of a large tertiary care private hospital in São Paulo, Brazil, between April and September 2015. The Strengthening the Reporting of Observational Studies in Epidemiology (STROBE) initiative was followed in the study.

The hospital is a 420-bed institution accredited by the Joint Commission International. The facility provides service to patients of middle to high socioeconomic status through health insurance or private healthcare service providers. On average, 84,000 patients are admitted through the ED every year. The triage protocol was developed by the emergency department staff of this service, is based on the Manchester Scale, and is divided into three levels: emergency, urgent and relatively urgent. Patient waiting times are: immediate; 1 to 2 hours; and more than 2 hours.

\section{Study population and inclusion and exclusion criteria}

Patients 18 years of age or older who presented with pain to the ED and were triaged as semi-urgent were invited to participate. Eligible patients were consecutively recruited when discharged from the ED, and those who agreed to participate in the study and signed the Informed Consent Form were included. Patients were excluded if they had language barriers that made them unable to understand Portuguese (Brazil), were directly referred to hospitalization at triage, or opted to abandon treatment during their ED stay.

\section{Study protocol}

The pain management protocol was developed by ED medical and nursing teams and validated institutionally by the hospital's Board of Directors. Only then was it implemented at the hospital ED in January 2013, after all ED nurses had received specific training. The protocol is characterized as nurse-initiated assessment and intervention based on an algorithm. It is based on assessment of severity of pain, patient's age, reported allergies, and analgesic medication prior to ED admission, among others, to determine the analgesic to be used. Oral paracetamol (acetaminophen) or dipyrone in standardized dosages are the first-choice medications. 
The protocol was implemented considering patient preferences, so patients with pain who were triaged as semi-urgent were offered the protocol and could accept it or refuse it. In the latter case, patient were managed using the conventional approach, described in further detail below.

The conventional approach was not having a standardized pain protocol available, so nurses were not allowed to assess pain and administer analgesics on their own initiative. Patients with pain waited for an ED physician evaluation and only then received analgesics. This was the comparison group.

In either case (intervention or routine care), patients admitted to the ED went through triage, received care, and were discharged to return home, kept under observation in the ED (receiving medications or not), or hospitalized.

\section{Data collection and patient follow-up}

Data collected included primary data obtained from patients, and secondary data obtained from the ED electronic patient registration and medical record information system. In this system is recorded patient characterization, admission diagnosis, triage information, administration of any procedures, medications, and non-pharmacological treatment, as well as time of administration. The data collection form developed for this study included a "patient section" and a "medical records section". Patients enrolled in the study were asked to complete the patient section of the data collection form, which included sociodemographic and education status, medication use prior to ED admission, pain characterization, and other self-reported clinical information. Self-reported pain at ED admission and discharge were assessed by a verbal numerical scale varying from 0 to 10 , with 0 indicating no pain and 10 the worst possible pain. For patients in the conventional/routine care group, the reason for not accepting the protocol was also assessed.

LOS assessment also considered intermediate measurements based on the flow of patients within the various sectors of the ED, including duration of triage (time between beginning and end of triage), wait time for medical care (time between end of triage and beginning of medical care); duration of medical care (time between beginning and end of medical care), and observation time (for patients put into observation, time between beginning and end of observation).

All data recorded on the data collection forms were entered into RedCap software by the information technology specialist in the hospital. The main outcomes of interest were LOS in the ED and pain relief.

\section{Analysis of results and statistics}

Sample size was estimated considering the main study objective, that is, to assess the difference in mean pain level pre- and post-ED admission, considering the intervention and conventional approach groups. Based on the mean and standard deviation of pain level numeric scores observed in individuals in the intervention (3.6; $\mathrm{SD}=3.43)$ and control (1.8; $\mathrm{SD}=2.64)$ groups from a pilot study of 100 patients, and assuming a 1:3 ratio of individuals in both groups, an $80 \%$ power, and $0.05 \%$ significance level, a sample size of 140 individuals was estimated.
Patients in both groups were characterized considering educational, demographic and clinical variables, LOS considering ED admission and discharge, and self-reported pain at ED admission and discharge.

Descriptive data are presented as means with standard deviations (SD) for continuous variables, as medians with interquartile ranges (IQR, 25th-75th percentile) for time variables and pain scale, and as frequencies for categorical variables. Comparisons between groups were made using Pearson's or Fisher's Chi-square test for categorical variables and the two-tailed Student's t-test, non-parametric Mann-Whitney U-test, or Kruskal-Wallis test for continuous variables, depending on whether the data met the assumption of normality. Differences in LOS between the two groups were analyzed using the two-tailed Student's t-test. Differences in pain relief in the two groups considering level of pain at triage and discharge were analyzed using the Kruskal-Wallis test. Differences between proportions of use of non-pharmacological treatment, pre-ED admission analgesic use, and analgesic provision in the ED and pain relief between the pre- and post-intervention period were analyzed using Pearson's Chi-square test. Differences and corresponding $95 \% \mathrm{Cls}$ of the median times to analgesics were calculated with the median test. A 0.05 significance level was considered, and a $p$-value $<0.05$ was considered statistically significant. Data was analyzed using Epi-Info ${ }^{\circ}$ v7 software.

\section{RESULTS}

A total of 185 people was included in this study; 55 (30\%) patients were in the intervention group, and 130 (70\%) patients were in the conventional approach-comparison group. Patients in the two groups were mostly similar regarding demographic and educational data, as shown in Table 1. However, patients in the intervention group were more likely to have taken pain medication in the four hours prior to ED admission ( $p=0.004)$.

The main reason reported by patients for refusing the pain protocol (and therefore being assigned to the conventional approach-control group) were personal preference to be seen and have medications prescribed by a physician ( $n=42,32.3 \%)$, and reporting a bearable level of pain ( $n=40,30.8 \%$ ) (Table 2 ). On the other hand, the main reason for doing so reported by patients who accepted the pain protocol was the expectation of immediate pain relief $(n=39,70.9 \%)$.

The pain assessment from triage to discharge, with stratification of the different care times, is outlined in Table 3. As expected, the level of pain in both groups at admission was significantly different, with significantly higher levels of pain reported by patients in the intervention group (Table 3). Nonetheless, the level of pain was similar in both groups at discharge, so a more significant reduction in the level of pain from triage to discharge was observed in the intervention group.

Of the 185 patients enrolled, 158 (85.4\%) were put under observation in the ED, 180 (97.3\%) were discharged to return home, $4(2.2 \%)$ were hospitalized, and $1(0.5 \%)$ gave up the service. Of the individuals under observation, 96 required analgesic medication during observation, of whom 32 were in the intervention group and 64 in the comparison group. When looking at levels of pain reported by patients put under observation, (Table 4), 62 patients did not required analgesic medication during observation (18 in the intervention group and 44 in the comparison group). 
Table 1 - Baseline characterization of patients enrolled in the study, São Paulo, São Paulo, Brazil, 2015

\begin{tabular}{|c|c|c|c|c|c|c|}
\hline \multirow{2}{*}{ Characteristics } & & \multicolumn{2}{|c|}{ Comparison group $(n=130)$} & \multicolumn{2}{|c|}{ Intervention group $(n=55)$} & \multirow{2}{*}{$p$ value } \\
\hline & & n & $\%$ & $\mathbf{n}$ & $\%$ & \\
\hline Gender & $\begin{array}{l}\text { Male } \\
\text { Female }\end{array}$ & $\begin{array}{l}25 \\
74\end{array}$ & $\begin{array}{l}43.1 \\
56.9\end{array}$ & $\begin{array}{l}56 \\
30\end{array}$ & $\begin{array}{l}45.5 \\
54.6\end{array}$ & 0.77 \\
\hline Age (years) & $\begin{array}{l}<30 \\
30-40 \\
40-50 \\
50-60 \\
>60\end{array}$ & $\begin{array}{l}27 \\
56 \\
24 \\
17 \\
6\end{array}$ & $\begin{array}{c}20.8 \\
43.1 \\
18.5 \\
13.1 \\
4.6\end{array}$ & $\begin{array}{c}17 \\
20 \\
11 \\
5 \\
2\end{array}$ & $\begin{array}{l}30.9 \\
36.4 \\
20.0\end{array}$ & 0.26 \\
\hline Education level & $\begin{array}{l}\text { High school } \\
\text { Intermediate } \\
\text { University (undergraduate) } \\
\text { Graduate } \\
\text { Not reported }\end{array}$ & $\begin{array}{c}7 \\
9 \\
100 \\
11 \\
3\end{array}$ & $\begin{array}{c}5.4 \\
6.9 \\
76.9 \\
8.5 \\
2.3\end{array}$ & $\begin{array}{c}4 \\
4 \\
42 \\
3 \\
2\end{array}$ & $\begin{array}{c}7.3 \\
7.3 \\
76.4 \\
5.4 \\
3.6\end{array}$ & 0.63 \\
\hline Analgesic use four hours before ED* & $\begin{array}{l}\text { No } \\
\text { Yes }\end{array}$ & $\begin{array}{l}95 \\
35\end{array}$ & $\begin{array}{l}73.1 \\
26.9\end{array}$ & $\begin{array}{l}28 \\
27\end{array}$ & $\begin{array}{l}50.9 \\
49.1\end{array}$ & 0.004 \\
\hline
\end{tabular}

Note: ${ }^{*}$ ED-Emergency Department.

Table 2 - Reasons for non-acceptance of the pain protocol $(\mathrm{n}=130)$, São Paulo, São Paulo, Brazil, 2015

\begin{tabular}{lcc}
\hline Reasons reported by patients & $\mathbf{n}$ & $\%$ \\
\hline Preference for being assessed by a physician & 42 & 32.3 \\
Bearable level of pain & 40 & 30.8 \\
Medication prior to ED* & 17 & 13.1 \\
Did not indicate reason & 13 & 10 \\
Perceived a quick waiting time to be seen by a physician & 5 & 3.8 \\
Other reasons reported & 13 & 10 \\
\hline
\end{tabular}

Note: *ED - Emergency Department.

When we stratify this analysis by subgroups of patients, we observe that among patients put under observation who did not receive analgesics during the observation period, the level of pain reported by patients in the intervention group was significantly higher than that for patients in the comparison group. Nonetheless, for the 96 patients who did receive analgesics during observation, the mean number of analgesics received was significantly higher for patients in the comparison group.

When considering patients who did not take analgesic medication in the 4 hours prior to presentation in the ED, the pain level reported by patients in the intervention group was also significantly higher than in the comparison group.

There were no differences in overall LOS, nor in the mean durations of triage, medical care, and observation time, when comparing the patients in the intervention and the conventional approach-comparison group (Table 5). The waiting time for medical care was significantly higher among patients who accepted the protocol than among those who refused it $(p=0.03)$.

Table 3 - Pain reported by patients enrolled in the study, by groups receiving the intervention or conventional approach, in the various phases of Emergency Department admission, São Paulo, São Paulo, Brazil, 2015

\begin{tabular}{|c|c|c|c|c|c|}
\hline \multirow{2}{*}{ Reported pain level } & \multicolumn{2}{|c|}{ Comparison group $(n=130)$} & \multicolumn{2}{|c|}{ Intervention group $(n=55)$} & \multirow{2}{*}{$p$ value } \\
\hline & Mean, SD** & Median (min-max) & Mean, SD** & Median (min-max) & \\
\hline At triage & $5.8 \pm 1.9$ & $6(1-10)$ & $7.1 \pm 1.7$ & $7(2-10)$ & 0.0001 \\
\hline At discharge & $4.0 \pm 2.3$ & $4(0-10)$ & $4.1 \pm 2.6$ & $4(0-9)$ & 0.83 \\
\hline Difference in pain (between triage and discharge) & $1.8 \pm 2.7$ & $1(-6-9)$ & $2.9 \pm 3.1$ & $2(-3-10)$ & 0.02 \\
\hline
\end{tabular}

Note: **SD - Standard Deviation.

Table 4 - Pain reported by patients enrolled in the study by condition and groups receiving the intervention or conventional approach, São Paulo, São Paulo, Brazil, 2015

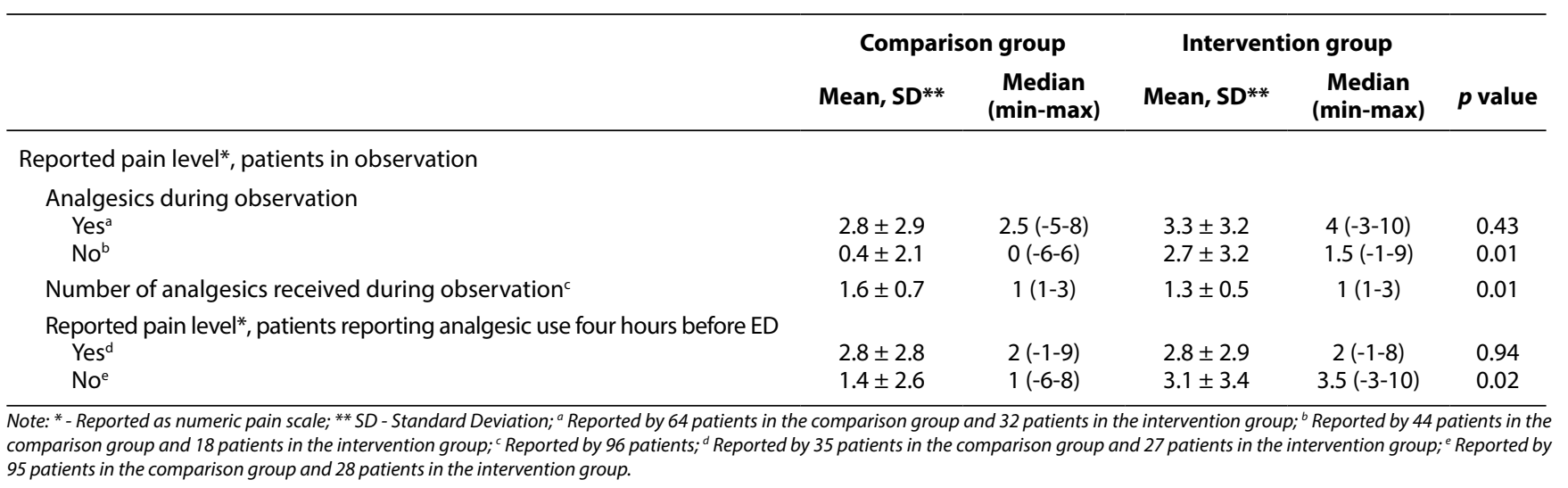


Table 5 - Length of stay in the Emergency Department and within each of its sectors, for patients enrolled in the study, by groups receiving the intervention or conventional approach, São Paulo, São Paulo, Brazil, 2015

\begin{tabular}{|c|c|c|c|c|c|}
\hline \multirow{2}{*}{$\begin{array}{l}\text { Mean LOS* } \\
\text { (in minutes) }\end{array}$} & \multicolumn{2}{|c|}{$\begin{array}{l}\text { Comparison group } \\
\qquad(n=130)\end{array}$} & \multicolumn{2}{|c|}{$\begin{array}{c}\text { Intervention group } \\
(\mathrm{n}=55)\end{array}$} & \multirow[b]{2}{*}{$p$ value } \\
\hline & Mean, SD** & $\begin{array}{c}\text { Median } \\
\text { (min-max) }\end{array}$ & Mean, SD** & $\begin{array}{c}\text { Median } \\
\text { (min-max) }\end{array}$ & \\
\hline Duration of triage & $2.6 \pm 0.7$ & $3(1-6)$ & $2.7 \pm 1.0$ & $3(1-6)$ & 0.54 \\
\hline Waiting time for medical care & $52.5 \pm 38.3$ & $45(2-246)$ & $61.9 \pm 37.2$ & $50(11-213)$ & 0.03 \\
\hline Duration of medical care & $5.3 \pm 3.3$ & $4(0-19)$ & $5.9 \pm 3.2$ & $5(0-18)$ & 0.11 \\
\hline Observation time & $152.5 \pm 90.8$ & $141(2-528)$ & $137.1 \pm 65.2$ & $137(0-295)$ & 0.65 \\
\hline Total ED* LOS $* * *$ & $199.2 \pm 108.6$ & $197(22-630)$ & $212.6 \pm 91.7$ & $225(29-397)$ & 0.17 \\
\hline
\end{tabular}

Note: *ED - Emergency Department.; ${ }^{*} S D$ - Standard Deviation; ${ }^{* * *}$ LOS - Length of Stay.

\section{DISCUSSION}

To our knowledge, this may be the first study in Brazil to demonstrate the impact of a nurse-initiated pain management protocol in EDs. The study showed that the protocol resulted in more significant pain relief and a lower number of analgesics required for pain management in adult patients admitted with pain in an ED who were triaged as semi-urgent. Our findings corroborate other evidence reported in developed countries, which has shown that nurse-initiated pain management protocols have resulted in reduced time to analgesia and care, decreased level of pain, and increased patient satisfaction ${ }^{(10-11,16-17)}$.

Nonetheless, a study conducted in Italy reported no difference in pain levels in patients with somatic pain receiving a pain management protocol in the $\mathrm{ED}^{(15)}$. This may be explained by the discomfort caused by pain, which was corroborated by a Swedish study that proposed predictors for treatment with analgesics and reported that when pain levels were higher, the likelihood of treatment with medications was also higher ${ }^{(14)}$.

Reduction in the number of analgesics required for pain management in EDs is an important finding, because it will have an impact on the expected staff time required to prepare and administer medications in EDs, potentially reducing staff time and risk of adverse events, effects, and errors related to medication administration ${ }^{(21)}$.

We were not able to demonstrate the impact of the pain protocol on LOS, as also reported in the literature, but our study was underpowered to assess $\operatorname{LOS}^{(1,14,22)}$. Adequate pain management remains a major challenge in EDs, particularly in the developing world, where there is still significant resistance to nurse-initiated protocols ${ }^{(23)}$. We were able to document this in our study, since patients refusing the pain protocol mostly did so due to a preference for being seen and prescribed for by a physician.

Concerning the variables sex and age, the profile of the study population, regardless of whether they accepted or refused the protocol, was similar to that of a study in Sweden ${ }^{(14)}$. However, the education variable, which was mostly higher, reflects the characteristics of the patients of this hospital. These findings show that patients who have access to private medical care have higher socioeconomic status, sometimes determined by having higher levels of education, thus corroborating an Australian study showing that patients usually visit EDs in private hospitals when they have higher purchasing power ${ }^{(24)}$. Regarding the medical specialty variable, the findings show that most patients seek care for their clinical complaints. The search for an ED is determined by actual patient needs and is linked to their main complaint, whether clinical, traumatic or surgical ${ }^{(25)}$.

Our findings suggest that most of the patients reaching the ED due to pain did not self-medicate prior to ED admission (66.5\%). This result is different from that reported by a study in Sweden, where nearly half $(51 \%)$ of the patients self-medicated prior to ED admission ${ }^{(14)}$. These different findings suggest the effects of patient cultural context, age and previous experience with pain management, or even the need for an opinion from a medical specialist regarding their main complaint.

The assessment of LOS within each section of the ED indicates that study participants were treated within the expected time for each stage of care. Although the wait times for medical treatment were significantly different between groups, the median wait time was five minutes, much lower than that reported in a study of 364 American hospitals, which reported a median of 45 minutes in both semi-urgent (mean 59 minutes) and non-urgent (mean 69 minutes) triaged patients ${ }^{(26)}$. In contrast, we observed a higher mean length of stay in observation (observation time) ( $3 \mathrm{~h}$ $36 \mathrm{~min})$, when compared with the observation time reported in the United States $(2 \mathrm{~h} 30 \mathrm{~min})^{(26)}$. This may be due to differences in the provision of care, private healthcare financing, and authorization for procedures, among others. Additional studies specifically designed to address this objective are required to better explain and understand these findings.

\section{Study limitations}

Our study had several limitations. First, patient preference determined allocation to the intervention and control groups, and this entails a bias in allocating patients, with pain likely to be more severe in the intervention group. However, this did not jeopardize our assessment of the impact of the intervention. On the contrary, it endorses the fact that patients with more severe pain should be prioritized for receiving pain protocols in the ED. Second, the sample size for this study was estimated considering the main study outcome, that is, pain resolution, and was not large enough to assess the difference of ED LOS between the two groups. The lack of impact observed may be a result of this small sample size and not a true finding. Finally, the study was conducted in a single private institution, located in a large metropolitan area of the country, and serving a patient population that comes from a high socioeconomic level and is more 
educated. As such, the results may not be generalizable to other institutions and patients with different characteristics, since the perception of pain and patient expectations for its management is heavily influenced by individual experience, and few studies have addressed this aspect.

\section{Contributions to nursing, health, or public policies}

It is essential to actively manage patient pain in EDs, in addition to carrying out activities to improve the quality of care in general. Pain management protocols are facilitators from a managerial point of view. Quality improvement activities based on education of nursing staff and documentation of pain in patient records have improved pain management for patients who seek care in health services. Pain protocols initiated by nurses effectively improve opportunities for and quality of care for patients with pain, which may become a public health policy.

\section{CONCLUSIONS}

The implementation of a nurse initiated pain management protocol in ED patients resulted in a more significant improvement in pain and decreased use of analgesics, when compared to patients receiving the conventional approach. Strategies to improve patient adherence and acceptance to such protocols are needed in selected settings to promote quality patient care in EDs.

\section{REFERENCES}

1. Sokoloff C, Daoust R, Paquet J, Chauny JM. Is adequate pain relief and time to analgesia associated with emergency department length of stay? a retrospective study. BMJ Open. 2014;4(3):e004288. https://doi.org/10.1136/bmjopen-2013-004288

2. Salway RJ, Valenzuela R, Shoenberger JM, MallonWK, Viccellio A. Emergency department (ED) overcrowding: evidence-based answers to frequently asked questions. Rev Méd Clín Las Condes. 2017;28(2):213-9. https://doi.org/10.1016/j.rmclc.2017.04.008

3. Marconato RS, Monteiro MI. Risk classification priorities in an emergency unit and outcomes of the service provided. Rev Latino-Am Enfermagem. 2017;25:e2974. http://dx.doi.org/10.1590/1518-8345.2345.2974

4. Malfussi LBH, Bertoncello KCG, Nascimento ERP, Silva SG, Hermida PMV, Walnice J. Agreement of an institutional risk classification assessment protocol. Texto Contexto Enferm. 2018;27(1):e4200016. https://doi.org/10.1590/0104-07072018004200016.

5. Giusti GD, Reitano B, Gili A. Pain assessment in the Emergency Department. Correlation between pain rated by the patient and by the nurse. an observational study. Acta Biomed. 2018;89(4-S):64-70. https://doi.org/10.23750/abm.v89i4-S.7055

6. Stauber MA. Advanced nursing interventions and length of stay in the emergency department. J Emerg Nurs. 2013;39(3):221-5. https://doi. org/10.1016/j.jen.2012.02.015

7. Parnass A, Greenbaum N, Glick M, Halpern P. Pain management framework in the emergency department: patterns in 40 emergency departments worldwide. Eur J Emerg Med.2016;23(4):311-4. https://doi.org/10.1097/MEJ.0000000000000299

8. Bertoncello KCG, Xavier LB, Nascimento ERP, Amante LN. Acute pain in emergency: evaluation and control through MacCaffery and Beebe instrument. J Health Sci [cited Sep 04 2020].2016;18(4):251-6. Available from: http://www.pgsskroton.com.br/seer/index.php/JHealthSci/ article/view/3701/3408

9. Chang $\mathrm{HL}$, Jung JH, Kwak YH, Kim DK, Lee JH, Jung JY, et. al. Quality improvement activity for improving pain management in acute extremity injuries in the emergency department. Clin Exp Emerg Med. 2018;30;5(1):51-9. https://doi.org/10.15441/ceem.17.260

10. Pierik JG, Berben SA, IJzerman MJ, Gaakeer MI, van Eenennaam FL, van Vugt AB, et al. A nurse-initiated pain protocol in the ED improves pain treatment in patients with acute musculoskeletal pain. Int Emerg Nurs. 2016;27:3-10. https://doi.org/10.1016/j.ienj.2016.02.001

11. Sepahvand $M$, Gholami M, Hosseinabadi R, Beiranvand A. The use of a nurse-initiated pain protocol in the emergency department for patients with musculoskeletal injury: a pre-post intervention study. Pain Manag Nurs. 2019;20(6):639-48. https://doi.org/10.1016/j. pmn.2019.02.012

12. Dewhirst S, Zhao Y, MacKenzie T, Cwinn A, Vaillancourt C. Evaluating a medical directive for nurse-initiated analgesia in the Emergency Department. Int Emerg Nurs. 2017;35:13-8. https://doi.org/10.1016/j.ienj.2017.05.005

13. Phillips JL, Jackson BE, Fagan EL, Arze SE, Major B, Zenarosa NR, et al. Overcrowding and its association with patient outcomes in a medianlow volume emergency department. J Clin Med Res. 2017;9(11):911-6. https://doi.org/10.14740/jocmr3165w

14. Muntlin Å̊, Carlsson M, Gunningberg L. To receive or not to receive analgesics in the emergency department: the importance of the pain intensity assessment and initial nursing assessment. Pain Manag Nurs. 2015;16(5):743-50. https://doi.org/10.1016/j.pmn.2015.04.004

15. Franceschi F, Marsiliani D, Alesi A, Mancini MG, Ojetti V, Candelli M, et al. A simplified way for the urgent treatment of somatic pain in patients admitted to the emergency room: the SUPER algorithm. Intern Emerg Med. 2015;10:985-92. https://doi.org/10.1007/ s11739-015-1304-7

16. Finn JC, Rae A, Gibson Nick, Swift R, Watters T, Jacobs IG. Reducing time to analgesia in the emergency department using a nurse-initiated pain protocol: a before-and-after study. Contemp Nurse. 2012;43(1):29-37. https://doi.org/10.5172/conu.2012.43.1.29

17. Fosnocht DE, Swanson ER. Use of a triage pain protocol in the ED. Am J Emerg Med. 2007;25:791-3. https://doi.org/10.1016/j.ajem.2006.12.020

18. Ministério da Saúde (BR). Humaniza SUS: Acolhimento e Classificação de Risco nos Serviços de Urgência [Internet]. 2009 [cited 2020 Sep 04]. Available from: http://bvsms.saude.gov.br/bvs/publicacoes/acolhimento_classificaao_risco_servico_urgencia.pdf 
19. Ministério da Saúde (BR). Portaria no 1.600 [Internet]. 2011 [cited sep 04 2020]. Available from: http://bvsms.saude.gov.br/bvs/saudelegis/ gm/2011/prt1600_07_07_2011.html

20. Mota-Guedes H, Aparecida-Araújo F, Pinto-Jr D, Amado-Martins JC, Machado-Chianca TC. Outcome assessment of patients classified through the Manchester Triage System in emergency units in Brazil and Portugal. Invest Educ Enferm. 2017;35(2):174-81. https://doi. org/10.17533/udea.iee.v35n2a06

21. Berdot S, Roudot M, Schramm C, Katsahian S, Durieux P, Sabatier B. Interventions to reduce nurses' medication administration errors in inpatient settings: a systematic review and meta-analysis. Int J Nurs Stud. 2016;53:342-50. https://doi.org/10.1016/j.ijnurstu.2015.08.012

22. Douma MJ, Drake CA, O'Dochartaigh D, Smith KE. A pragmatic randomized evaluation of a nurse-initiated protocol to improve timeliness of care in an urban emergency department. Ann Emerg Med. 2016;68(5):546-52. https://doi.org/10.1016/j.annemergmed.2016.06.019

23. Reis GAX, Oliveira JLC, Ferreira AMD, Vituri DW, Marcon SS, Matsuda LM. Difficulties to implement patient safety strategies: perspectives of management nurses. Rev Gaúcha Enferm. 2019;40(spe):e20180366. https://doi.org/10.1590/1983-1447.2019.20180366

24. He J, Hou XY, Toloo GS, FitzGerald G. Patients' choice between public and private hospital emergency departments: a cross-sectional survey. EMA. 2017;29(6):635-42. https://doi.org/10.1111/1742-6723.12841

25. Gebru AA, Mosadeghrad AM, Sari AA, Tafesse TB, Kahsay WG. Client satisfaction on emergency department services and quality of emergency medical care in Ethiopia: a systematic review. Hum Antibodies. 2019;27(S1):23-31. https://doi.org/10.3233/HAB-190367

26. Horwitz LI, Green J, Bradley EH. US emergency department performance on wait time and length of visit. Ann Emerg Med. 2010;55(2):13341. https://doi.org/10.1016/j.annemergmed.2009.07.023 